\title{
Pulmonary vascular structure in patients dying after a Fontan procedure The lung as a risk factor
}

\author{
ERNESTO JUANEDA, SHEILA G HAWORTH \\ From the Department of Paediatric Cardiology, Institute of Child Health, London
}

SUMmary Pulmonary vascular structure was analysed in the lungs of 12 patients who had had a Fontan repair, 11 of whom died. Of the eight patients with a low pulmonary blood flow preoperatively, pulmonary vascular structure was almost normal in seven, but in the remaining patient many intra-acinar arteries contained organised occlusive thrombi. Of the four patients with an increased pulmonary blood flow immediately before operation, there was a significant increase in pulmonary vascular smooth muscle despite three of the patients having had a pulmonary arterial band. The findings suggest that it is more difficult for patients with an increased pulmonary blood flow to fulfil the Fontan criteria for repair, and even when the pulmonary vascular resistance is $<4 \mathrm{units} / \mathrm{m}^{2}$ there may be significant pulmonary vascular abnormalities likely to increase right atrial afterload and prejudice the outcome of a Fontan repair.

The Fontan procedure, connection of the right atrium either to the pulmonary artery directly or via a subpulmonary ventricular chamber, provides a physiological correction for tricuspid atresia and other types of double inlet ventricle..$^{1-5}$ Pulmonary blood flow is dependent on the gradient between right and left atrial pressures, and so pulmonary vascular resistance must be as low as possible. ${ }^{6}$ Immediately after operation any increase in right atrial afterload increases right atrial pressure until leakage occurs in the systemic capillaries. The selection criteria for a Fontan procedure demand that the mean pulmonary arterial pressure be $\leqslant 15 \mathrm{~mm} \mathrm{Hg}$, pulmonary vascular resistance be $<4$ units $/ \mathrm{m}^{2}$, and that the ratio of the diameter of the main pulmonary artery to that of the aorta be $\geqslant 0.75$ with normal sized pulmonary arteries. ${ }^{7}$ The pulmonary vascular bed may, however, have been compromised by palliative surgery in patients whose intracardiac anatomy is theoretically suitable for a Fontan repair. The clinical condition of most children with tricuspid atresia demands that a systemic-pulmonary anastomosis be performed before they reach the recommended age for a Fontan procedure of 4 years. ${ }^{7}$ Shunt operations may be compli-

Requests for reprints to Dr S G Haworth, Hospital for Sick Children, Great Ormond Street, London WCIN 3JH.

Accepted for publication 3 July 1984 cated by the later development of pulmonary vascular disease or distortion of the pulmonary arteries, and even in those patients with a normal pulmonary arterial pressure and resistance the pulmonary vasculature is not necessarily normal. A low pulmonary blood flow may be associated with intimal thromboses, particularly in the presence of polycythaemia. ${ }^{8}$ An increase in flow with or without an increase in pressure may be associated with an increase in smooth muscle in small precapillary arteries. ${ }^{9}$ The Fontan procedure is also used in a few patients in whom the pulmonary artery has been banded previously to reduce the pulmonary arterial pressure and flow, on the assumption that pulmonary arterial medial hypertrophy will regress.

This report describes the structure of the pulmonary vascular bed in 12 patients, 11 of whom died immediately or soon after a Fontan repair.

\section{Patients and methods}

Twelve patients with either tricuspid atresia, tricuspid stenosis, other type of double inlet ventricle, or pulmonary atresia with an intact ventricular septum had a Fontan repair at one of three different cardiac centres between 1980 and 1983. Before the Fontan procedure seven patients had had a systemicpulmonary shunt, one a pulmonary valvotomy fol- 
lowed by a Barratt's operation, and one a balloon atrial septostomy only. Three other patients had required banding of the pulmonary artery, and one had had a coarctation of the aorta repaired at the same time. The Table shows the haemodynamic findings at the time of the Fontan repair. Clinically, immediately before the Fontan procedure the pulmonary blood flow was low in eight patients (cases 1-8) and greater than the systemic flow in four cases (9-12). The time interval between the last preoperative cardiac catheterisation study and repair was three months or less in nine patients and between six and nine months in three. The pulmonary artery was entered in eight cases. The mean pulmonary arterial pressure varied between 10 and $28 \mathrm{~mm} \mathrm{Hg}$, exceeding the recommended upper limit of $15 \mathrm{~mm} \mathrm{Hg}$ in five cases. ${ }^{7}$ Pulmonary arteriolar resistance varied between 0.85 and 5.4 units $/ \mathrm{m}^{2}$, but exceeded the upper limit of 4 units $/ \mathrm{m}^{2}$ in only one case. ${ }^{7}$ The mean left atrial pressure and left ventricular end diastolic pressure was within normal limits in all cases. On angiography both pulmonary arteries were of good size except the left pulmonary artery in the patient in case 2 , which was not opacified. Clinically and at angiography the shunt was patent in all patients who had such a procedure done. In one patient (case 9) the coarctation had been repaired successfully. None of the patients had clinical or haemodynamic evidence of mitral valve disease, but at necropsy the mitral valve was abnormal in the patient in case 6 , the chordae being short and thickened. In the eight cases with a low pulmonary blood flow the haemoglobin concentration was $15.7-22.3 \mathrm{~g} / \mathrm{dl}$, and in the four cases with higher flow it was, 13-15 g/dl.

At operation, a subpulmonary ventricular chamber was incorporated into the Fontan repair in six cases. In the patient in case 9 with transposition of the great arteries the ventricular septal defect was restrictive, and therefore the aorta was anastomosed to the proximal pulmonary artery and the distal pulmonary artery was anastomosed to the right atrium. In the patient in case 12 immediately after the Fontan repair the mean pressure in the right atrium was $20 \mathrm{~mm} \mathrm{Hg}$ and in the left $5 \mathrm{~mm} \mathrm{Hg}$. The Fontan repair was therefore taken down and the ventricle septated, after which the mean right atrial pressure was $12 \mathrm{~mm} \mathrm{Hg}$. In all 12 cases the mean right atrial pressure was high immediately after the Fontan repair, being $10-20 \mathrm{~mm}$ $\mathrm{Hg}$ in the patients in cases $1-8$ and $20-25 \mathrm{~mm} \mathrm{Hg}$ in those in cases $9-12$. The mean left atrial pressure was

Table Diagnosis and haemodynamic data

\begin{tabular}{|c|c|c|c|c|c|c|c|c|c|c|}
\hline \multirow{2}{*}{$\begin{array}{l}\text { Case } \\
\text { No }\end{array}$} & \multirow[t]{2}{*}{ Diagnosis } & \multirow{2}{*}{$\begin{array}{l}\text { Age } \\
\text { at } \\
\text { death } \\
(\boldsymbol{v r})\end{array}$} & \multirow{2}{*}{$\begin{array}{l}\text { Type of palliative } \\
\text { surgery (age) }\end{array}$} & \multicolumn{7}{|c|}{ Preoperative haemodynamic values } \\
\hline & & & & $\begin{array}{l}\text { Mean } \\
P A P \\
(m m \mathrm{Hg})\end{array}$ & $\begin{array}{l}\text { Mean } \\
\text { SAP } \\
(m m \mathrm{Hg})\end{array}$ & $Q p: Q s$ & $R p: R s$ & $\begin{array}{l}R p a \\
\left(u / m^{2}\right)\end{array}$ & $\begin{array}{l}\% \mathrm{O}_{2} \\
\text { sat }\end{array}$ & $\begin{array}{l}H b \\
(g / d l)\end{array}$ \\
\hline 1 & Tricuspid atresia $\left(\mathrm{Ia}^{\star}\right)$ & $2 \cdot 0$ & $\begin{array}{l}\text { Right pulmonary artery- } \\
\text { aortic shunt }(3 \mathrm{~d})\end{array}$ & - & 71 & - & - & - & 59 & $22 \cdot 3$ \\
\hline 2 & $\begin{array}{l}\text { Hypoplastic right ventricle } \\
\text { and left pulmonary artery }\end{array}$ & $y^{3 \cdot 1}$ & $\begin{array}{l}\text { Pulmonary valvotomy } \\
\text { (1 mth), Barratt's } \\
\text { operation (1 yr) }\end{array}$ & - & 60 & - & - & - & 74 & 20 \\
\hline 3 & Tricuspid atresia $\left(\mathbf{I a}^{\star}\right)$ & $3 \cdot 8$ & $\begin{array}{l}\text { Right Blalock-Taussig } \\
\text { shunt ( } 3 \mathrm{mth})\end{array}$ & - & 65 & - & - & - & 81 & $18 \cdot 6$ \\
\hline 4 & $\begin{array}{l}\text { Pulmonary atresia with } \\
\text { intact ventricular system }\end{array}$ & $6 \cdot 8$ & $\begin{array}{l}\text { Balloon atrial septostomy } \\
\text { ( } 3 \text { d), Waterson } \\
\text { shunt ( } 5 \text { d) }\end{array}$ & 20 & 75 & - & - & $2 \cdot 2$ & 84 & $16 \cdot 3$ \\
\hline 5 & Tricuspid atresia $\left(\mathrm{Ib}^{\star}\right)$ & 8.0 & $\begin{array}{l}\text { Right Blalock-Taussig } \\
\text { shunt }(5 \mathrm{yr})\end{array}$ & - & 70 & - & - & - & 83 & $19 \cdot 0$ \\
\hline 6 & $\begin{array}{l}\text { Dextrocardia, double inlet } \\
\text { ventricle (in determinate } \\
\text { type), tricuspid atresia, } \\
\text { infundibular pulmonary } \\
\text { stenosis }\end{array}$ & 8.5 & $\begin{array}{l}\text { Right Blalock-Taussig } \\
\text { shunt }(2.5 \mathrm{yr})\end{array}$ & 10 & 75 & 1 & 0.07 & 1.5 & 88 & $18 \cdot 0$ \\
\hline 7 & Tricuspid atresia $\left(I b^{\star}\right)$ & 9.9 & $\begin{array}{l}\text { Left and right Blalock- } \\
\text { Taussig shunt }(5 \mathrm{mth} \\
\text { and } 6 \mathrm{yr})\end{array}$ & 18 & 80 & 0.6 & 0.2 & $1 \cdot 3$ & 87 & $15 \cdot 7$ \\
\hline 8 & $\begin{array}{l}\text { Tricuspid atresia }\left(\mathrm{Ia}^{\star}\right) \\
\text { stenosis of right } \\
\text { pulmonary artery }\end{array}$ & $12 \cdot 2$ & $\begin{array}{l}\text { Waterson shunt }(5 \mathrm{yr}) \\
\text { left Blalock-Taussig } \\
\text { shunt }(9 \mathrm{yr})\end{array}$ & 12 & 60 & - & 0.02 & $1 \cdot 3$ & 89 & $20 \cdot 0$ \\
\hline 9 & $\begin{array}{l}\left.\text { Tricuspid atresia (III }{ }^{\star}\right), \\
\text { coarctation of the aorta }\end{array}$ & $1 \cdot 0$ & $\begin{array}{l}\text { Pulmonary artery band, } \\
\text { repair of coarctation } \\
(1 \mathrm{~m})\end{array}$ & 14 & 44 & $5 \cdot 2$ & 0.04 & 0.85 & 77 & 13 \\
\hline 10 & Tricuspid atresia $\left(\right.$ IIc $\left.^{\star}\right)$ & $2 \cdot 4$ & $\begin{array}{l}\text { Balloon atrial septostomy } \\
(2 \mathrm{~d})\end{array}$ & 28 & 64 & 3 & 0.2 & $1 \cdot 4$ & 83 & $14 \cdot 0$ \\
\hline 11 & Tricuspid atresia $\left(I c^{\star}\right)$ & $6 \cdot 6$ & $\begin{array}{l}\text { Pulmonary artery band } \\
(1 \mathrm{yr})\end{array}$ & 25 & 60 & 1.7 & 0.6 & $5 \cdot 4$ & 80 & $15 \cdot 0$ \\
\hline 12 & $\begin{array}{l}\text { Double inlet ventricle } \\
\text { (left ventricular typet) }\end{array}$ & $12 \cdot 6$ & $\begin{array}{l}\text { Pulmonary artery band } \\
\text { (2 yr) }\end{array}$ & 17 & 80 & $3 \cdot 1$ & 0.04 & 1 & 93 & $14 \cdot 6$ \\
\hline
\end{tabular}

PAP pulo PAP, pulmonary arterial pressure; $\mathrm{SAP}$, systemic arterial pressure, $\mathrm{O}_{2}$ sat, systemic arterial oxygen saturation. systemic resistance ratio; Rpa, pulmonary arteriolar resistance; $\mathrm{O}_{2}$ sat, क 然 
5-10 $\mathrm{mm} \mathrm{Hg}$. The mean pulmonary arterial pressure was measured immediately after the Fontan repair in six of the 12 cases and was $17-25 \mathrm{~mm} \mathrm{Hg}$. In the patient in case 12 the mean pulmonary arterial pressure after septation was $40 \mathrm{~mm} \mathbf{~ H g}$. Examination of the phasic pressure traces indicated some obstruction to flow between the right atrium and conduit in two patients (cases 5 and 10) and between the outlet chamber and the pulmonary artery in one (case 8) (personal communication, $\mathrm{C}$ Bull). In the presence of a high right atrial pressure tolazoline or nitroprusside or both was given to eight of the 12 patients in an attempt to reduce pulmonary arteriolar resistance as much as possible, with little effect.

A lung biopsy was performed at the time of operation in the patient in case 8. One year after the operation this patient had a mean pulmonary arterial pressure of $9 \mathrm{~mm} \mathrm{Hg}$ and a pulmonary arteriolar resistance of $2.8 \mathrm{units} / \mathrm{m}^{2}$. Eleven patients died, five within 48 hours and all within 21 days after operation.

\section{PATHOLOGICAL TECHNIQUES}

Postmortem lung tissue was examined in 11 patients and biopsy tissue in one. One of the necropsy specimens (case 1) was injected with a barium sulphate gelatin mixture. ${ }^{10}$ The tissue was embedded in paraffin and $4 \mu \mathrm{m}$ sections were stained with Miller's elastic stain counterstained with van Gieson's stain and with haematoxylin and eosin. The muscularity, size, and number of the peripheral pulmonary arteries were determined using quantitative morphometric techniques. ${ }^{10}$ Pulmonary arterial muscularity was assessed by determining mean percentage arterial medial thickness in arteries grouped according to their external diameter and by determining the proportion of muscular, partially muscular, and nonmuscular arteries accompanying terminal bronchioli respiratory bronchioli and alveolar ducts. In each case the mean external diameter of arteries accompanying terminal and respiratory bronchioli and alveolar ducts was determined and the number of intra-acinar arteries assessed by determining the ratio of alveoli to arteries. In each case the mean percentage arterial medial thickness and the mean external diameter of arteries accompanying each type of airway was compared with the normal for age using Student's $t$ test. ${ }^{11} 12$

\section{Results}

The lungs appeared normal macroscopically in all 11 necropsy specimens, except in the patient in case 2, who had extensive fibrous adhesions over both lungs after a Barratt's operation. The lungs appeared congested and oedematous in six cases. Microscopically, in all 12 cases the airway and alveolar structure appeared normal. In the 10 cases in which both lungs were available for examination there were no significant differences in airway or vascular structure between the two lungs.

Reduced pulmonary blood flow (cases 1-8)-Mean percentage arterial medial thickness was normal in arteries of all sizes except in two patients (cases 1 and 4 ), and in these an increase in muscularity was not statistically significant (Fig. 1). Examination of the structure of arteries accompanying peripheral airways showed that muscle was normally distributed along the arterial pathway in all cases. Mild eccentric intimal proliferation and fibrosis was present in the small muscular preacinar arteries in the patients in cases 4 and 6 and in the intra-acinar arteries in those in cases $2,4,6$, and 8 . In the patient in case 6 many intraacinar arteries contained organised and recanalised thrombi (Fig. 2). Within the acinus, the mean external diameter of arteries accompanying respiratory bronchioli and alveolar ducts was at the lower limit of the normal range in the seven uninjected specimens and significantly smaller than normal in the one injected specimen (case 1$)(p<0.05)$. On the postmortem arteriogram the lumen diameter of the preacinar arteries in the patient in case 1 was also small, being $75 \%$ of the normal value for age. In all eight cases the alveolar to arterial ratio was normal and varied between 10.4 and 11.2 (normal range 8.211.2). ${ }^{11}$ The pulmonary veins appeared normal in all except one patient (case 6), in whom several showed mild eccentric intimal fibrosis. The bronchial arteries

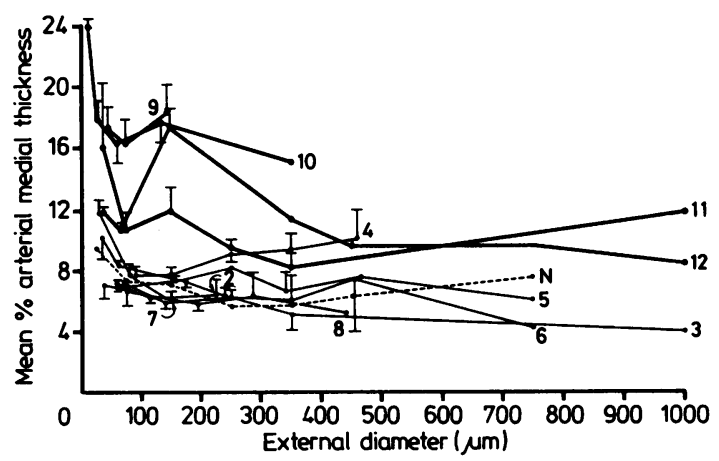

Fig. 1 Mean percentage arterial medial thickness in relation to external diameter in seven patients (uninjected tissue) with atresia, hypoplasia, or stenosis of the tricuspid valve, or with pulmonary atresia and a low pulmonary blood flow (thin lines), four with tricuspid atresia or other type of double inlet ventricle and increased pulmonary blood flow (thick lines) compared with the normal $(N)$ (interrupted line). The numbers indicate case numbers. Values for the patient in case 1 (injected tissue) are not shown. Bars represent SEM. 


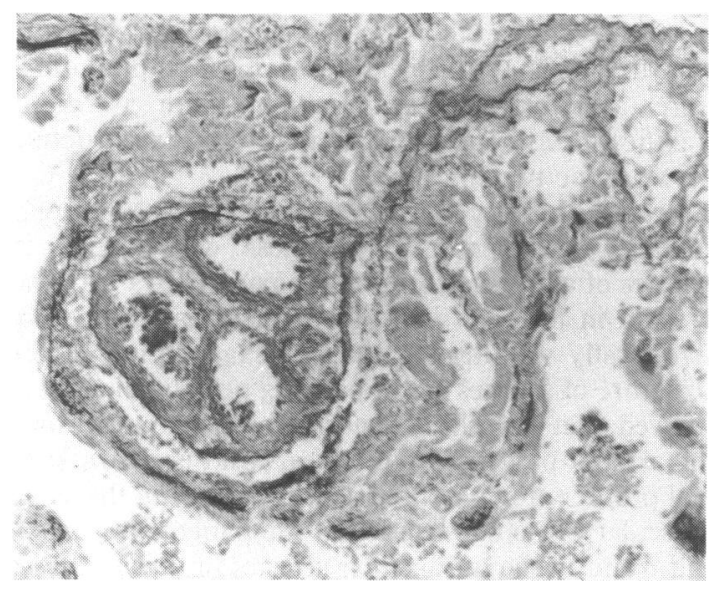

Fig. 2 Case 6: photomicrograph showing an organised thrombus with recanalisation in an artery accompanying $a$ respiratory bronchiolus: (Magnification $\times 200$, Miller's elastic stain counterstained with van Gieson's stain.)

had a normal appearance in all except the patients in cases 2 and 6, in whom they were enlarged.

Increased pulmonary blood flow (cases 9-12)-In all four patients mean percentage arterial medial thickness was above the normal for age in arteries of all sizes, significantly so in arteries of all size ranges in the patient in case $12(p<0.05)$ and in arteries in some of the size ranges below $200 \mu \mathrm{m}$ in diameter in the other three $(p<0.05)$ (Fig. 1). Examination of the structure of arteries accompanying peripheral airways showed that the distribution of muscle along the arterial pathway was normal in the patients in cases 11 and 12 but increased in those in cases 9 and 10, in whom $97 \%$ and $100 \%$ of alveolar duct arteries respectively were entirely muscularised compared with the normal range of $43-46 \% .{ }^{11} A$ thin eccentric layer of intimal fibrosis was present in several terminal bronchiolar arteries in the patients in cases 10 and 11 . None showed concentric intimal proliferation. The mean external diameter of arteries accompanying peripheral airways was greater than normal in the patient in case 10 but not significantly so, normal in those in cases 9 and 11 , and reduced in that in case 12 , significantly so at respiratory bronchiolar level $(p<0.02)$. In all four patients the alveolar to arterial ratio was normal, varying between 11.6 and 12.5 .

\section{Discussion}

The Fontan operation was originally described for patients with tricuspid atresia who had a low pulmonary blood flow, and the present study includes eight such patients. In this group the mean pulmonary arterial pressure was slightly higher than the recommended upper limit of $15 \mathrm{~mm} \mathrm{Hg}$ in two patients, but was normal, or thought to be normal, in the remaining patients with a low pulmonary blood flow and an appreciably increased haemoglobin concentration. The size of the extra pulmonary arteries was adequate in all. Nevertheless, seven patients died soon after the repair. Immediately after the operation the mean right atrial pressure was high in all cases, and this could have been due either to conduit obstruction, to structural and functional abnormalities of the mitral valve and left ventricle, to structural abnormalities of the pulmonary vascular bed, or to more than one of these factors. Examination of pulmonary vascular structure showed that in all eight cases the muscularity of the peripheral pulmonary arteries was normal, and the intrapulmonary arteries showed little reduction in size. In only one patient with a low pulmonary blood flow was the pulmonary vascular bed probably responsible for the fatal outcome. In this patient the mean pulmonary arterial pressure preoperatively was only $10 \mathrm{~mm} \mathrm{Hg}$, but many intra-acinar arteries contained well organised recanalised thrombi.

The present study shows that the pulmonary vessels may contain thrombi in patients with a low pulmonary blood flow who fulfil the criteria for a Fontan operation. There were four such cases, although the thrombi were probably obstructive in only one. The association of polycythaemia and thrombus formation in the lungs was well described in the early days of paediatric cardiology, and most of the patients in the present study with a low pulmonary blood flow had a haemoglobin concentration $>16 \mathrm{~g} / \mathrm{dl}$. This problem might be avoided by carrying out the repair at a younger age, soon after the shunt operation. A shunt operation is probably necessary in most patients to achieve satisfactory growth of the pulmonary vessels before a Fontan repair is carried out. A lung biopsy is unlikely to be helpful in evaluating the severity of thrombotic disease, since a biopsy specimen cannot be expected to be representative of the entire pulmonary vascular bed in these circumstances.

In the present study, in four patients with a high pulmonary blood flow the mean pulmonary arterial pressure before operation exceeded $15 \mathrm{~mm} \mathrm{Hg}$ in three, although pulmonary arteriolar resistance was increased in only one and the size of the pulmonary arteries was adequate in all. Immediately after the Fontan repair in all four patients the mean right atrial pressure was $\geqslant 20 \mathrm{~mm} \mathrm{Hg}$ and the structural abnormalities found in the pulmonary vessels probably increased right atrial afterload. All patients showed a considerable increase in pulmonary vascular smooth muscle, despite the pulmonary arteries having been banded in three. Regression of medial hypertrophy might have been less than expected in two of the patients, in whom the pulmonary arteries were banded late, at one year or more. 
Preoperatively, of the three banded patients only one showed a slight increase in pulmonary arterial pressure. In other cardiac abnormalities the result would probably have been satisfactory and associated with a successful intracardiac repair. It seems likely that in patients destined for a Fontan repair the pulmonary artery should be banded more tightly than in patients whose intracardiac anatomy is such that a ventricle will support the pulmonary circulation after the operation. In practice it is frequently difficult to band patients with a double inlet ventricle and a high pulmonary blood flow effectively perhaps because a large amount of pulmonary vascular smooth muscle is present even in early infancy. There are patients who have had the pulmonary artery banded, who still have an increase in pulmonary blood flow immediately before the Fontan repair and who have survived, but it does seem likely that the risk of a Fontan repair is greater in these patients than in those with a low pulmonary blood flow preoperatively. Gale et al ${ }^{13}$ have shown that an increased pulmonary arterial pressure does not necessarily mean that the patient is inoperable as long as the pulmonary arteriolar resistance is "acceptable," but the mortality was higher in these patients. In selecting patients with an increase in pulmonary blood flow for a Fontan repair a preoperative lung biopsy should be helpful since an increase in muscularity and the more advanced changes of pulmonary vascular disease are evenly distributed throughout the pulmonary vascular bed.

In the postoperative period drugs given to dilate the pulmonary vasculature are likely to evoke a different response in these two groups of patients, being unlikely to benefit those with a normal amount of pulmonary vascular smooth muscle and helpful to those with pulmonary arterial medial hypertrophy. After cardiopulmonary bypass the pulmonary vasculature can be labile in patients with an increase in pulmonary vascular smooth muscle, and episodic pulmonary hypertension may be treated successfully with pulmonary vasodilators. ${ }^{14}$

The present study shows that structural abnormalities in the pulmonary vasculature may increase the risk of operation in patients who fulfil the criteria for a Fontan repair or who have only a modest increase in pulmonary arterial pressure and vascular resistance above the recommended level. Gale et al, however, operated on 18 patients who did not fulfil the Fontan criteria, $78 \%$ of whom survived. ${ }^{13}$ In addition, they successfully repaired five patients with tricuspid atresia type $\mathrm{C}$, in whom the pulmonary artery had been banded. In order to assess more precisely how the structure of the pulmonary vasculature may affect the outcome of a Fontan repair, the lungs should be examined histologically at the time of repair in a large series of patients in whom the pressure gra- dient across the pulmonary vascular bed and the cardiac output are closely monitored postoperatively.

The findings in the present study suggest that in patients with tricuspid atresia or other type of double inlet ventricle with a reduced pulmonary blood flow pulmonary arterial structure is almost normal and unlikely to prejudice the outcome of a Fontan repair. Thrombotic occlusion of small pulmonary arteries is, however, possible. By contrast, in those with an excessive pulmonary blood flow preoperatively, even when the pulmonary arterial pressure is normal or only slightly raised, there may be a significant increase in pulmonary arterial muscularity. Immediately after operation an increase in pulmonary arterial muscularity will increase the resistance to blood flow through the lung, increase the lability of the pulmonary vascular bed in a lung recently damaged by cardiopulmonary bypass, and therefore increase right atrial afterload. The risk of a Fontan repair is probably greater in these than in patients with a low pulmonary blood flow preoperatively, but in this group a preoperative lung biopsy should help in selecting patients for repair.

We thank the physicians and surgeons of the Deutsches Herzzentrum, Munich, and of Southampton General Hospital for permission to study their cases.

This study was supported by the British Heart Foundation.

\section{References}

1 Fontan F, Baudet E. Surgical repair of tricuspid atresia. Thorax 1971; 26: 240-8

2 Kreutzer GO, Vargas FJ, Schlichter AJ, et al. Atriopulmonary anastomosis. $\mathcal{F}$ Thorac Cardiovasc Surg 1982; 83: 427-36.

3 Björk VO, Olin CL, Bjarke BB, Thorén LA. Right atrial-right ventricular anastomosis for correction of tricuspid atresia. F Thorac Cardiovasc Surg 1979; 77: 452-8.

4 Yacoub MH, Radley-Smith R. Use of a valved conduit from right atrium to pulmonary artery for "correction" of single ventricle. Circulation 1976; 54 (suppl 3): 63-70.

5 Gale AW, Danielson GK, McGoon DC, Mair DD. Modified Fontan operation for univentricular heart and complicated congenital lesions. $\mathcal{f}$ Thorac Cardiovasc Surg 1979; 78: 831-8.

6 Bull C, de Leval MR, Stark J, Taylor JFN, Macartney FJ, McGoon D. Use of a subpulmonary ventricular chamber in the Fontan circulation. $\mathcal{F}$ Thorac Cardiovasc Surg 1983; 85: 21-31.

7 Choussat A, Fontan F, Besse P, Vallot F, Chauve A, Bricaud H. Selection criteria for Fontan's procedure. In: Anderson RH, Shinebourne EA, eds. Paediatric cardiol- 
ogy 1977. Edinburgh: Churchill Livingstone, 1978: $559-66$.

8 Heath D, Dushane JW, Wood EH, Edwards JE. The aetiology of pulmonary thrombosis in cyanotic congenital heart disease with pulmonary stenosis. Thorax 1958; 13: 213-7.

9 Rabinovitch M, Haworth SG, Vance Z, et al. Early pulmonary vascular changes in congenital heart disease studied in biopsy tissue. Hum Pathol 1980; 11 (suppl): 499-509.

10 Hislop A, Reid L. New pathological findings in emphysema of childhood. I Polyalveolar lobe with emphysema. Thorax 1970; 25: 682-90.

11 Haworth SG, Hislop AA. Pulmonary vascular development: normal values of peripheral vascular structure. Am f Cardiol 1983; 52: 578-83.

12 Hislop A, Reid L. Pulmonary arterial development during childhood: branching pattern and structure. Thorax 1973; 28: 129-35.

13 Gale AW, Danielson GK, McGoon DC, Wallace RB, Mair DD. Fontan procedure for tricuspid atresia. Circulation 1980; 62: 91-6.

14 Jones ODH, Shore DF, Rigby ML, et al. The use of tolazoline hydrochloride as a pulmonary vasodilator in potentially fatal episodes of pulmonary vasoconstriction after cardiac surgery in children. Circulation 1981; 64 (suppl II): 134-9.

15 Tandon $R$, Edwards JE. Tricuspid atresia: a reevaluation and classification. I Thorac Cardiovasc Surg 1974; 67: 530-42. 